\title{
André Gide, Paul-Albert Laurens, Correspondance
} 1891-1934

\section{Elena Mazzoleni}

\section{(2) OpenEdition}

\section{Journals}

\section{Edizione digitale}

URL: http://journals.openedition.org/studifrancesi/5417

DOI: 10.4000/studifrancesi.5417

ISSN: 2421-5856

\section{Editore}

Rosenberg \& Sellier

\section{Edizione cartacea}

Data di pubblicazione: 1 dicembre 2016

Paginazione: 561

ISSN: 0039-2944

\section{Notizia bibliografica digitale}

Elena Mazzoleni, «André Gide, Paul-Albert Laurens, Correspondance 1897-1934 », Studi Francesi [Online], 180 (LX | III) | 2016, online dal 01 janvier 2017, consultato il 18 septembre 2020. URL : http:// journals.openedition.org/studifrancesi/5417 ; DOI : https://doi.org/10.4000/studifrancesi.5417

Questo documento è stato generato automaticamente il 18 settembre 2020.

\section{(c) $(7)$}

Studi Francesi è distribuita con Licenza Creative Commons Attribuzione - Non commerciale - Non opere derivate 4.0 Internazionale. 


\title{
André Gide, Paul-Albert Laurens, Correspondance 1891-1934
}

\author{
Elena Mazzoleni
}

\section{NOTIZIA}

ANDRÉ GIDE, PAUL-ALBERT LAURENS, Correspondance 1891-1934, édition établie par Pierre

Masson et Jean-Michel Wittmann, Lyon, Presses Universitaires de Lyon, 2015, 231 pp.

1 L'edizione della corrispondenza fra André Gide e Paul-Albert Laurens, curata da Pierre Masson e da Jean-Michel Wittmann, comprende le lettere che l'artista e lo scrittore si sono scambiati tra il 1891 e il 1934. I manoscritti di Gide destinati a Laurens e alla famiglia dell'amico sono attualmente conservati presso la fondazione Catherine Gide, mentre quelli di Laurens sono depositati presso la biblioteca letteraria Jacques Doucet. In questa edizione il corpus, che consta di un centinaio di lettere, è corredato di un ampio apparato di note, di una bibliografia specifica e di un indice dei nomi propedeutico alla lettura.

2 Stando ai curatori, il filo conduttore della corrispondenza è il rapporto d'amicizia che, per più di quarant'anni, ha unito i due autori. Un legame profondo e simbiotico in grado di superare, da un lato, i confini individuali, quali ad esempio le inclinazioni più intime in ambito sessuale o religioso; e dall'altro, le scelte artistiche, come lo stile pittorico di Laurens, a cui Gide si è sempre mostrato indifferente, se non estraneo: «Si différents dans leur manière de construire et leur vie, et leur œuvre, ils ne cessèrent jamais de s'aimer d'une amitié profonde...» (p. 23).

3 La nota introduttiva all'edizione è incentrata sul valore decisivo che questa amicizia ha assunto nella vita dello scrittore francese. Nata in un momento particolarmente complicato della vita di Gide che ha coinciso con la stesura dei Cahiers d'André Walter, essa avrebbe avuto un ruolo formativo sia dal punto di vista esistenziale, sia da quello della creazione letteraria. A seguito del viaggio in Africa intrapreso, insieme all'amico, tra il 1893 e il 1894, Gide aveva iniziato a frequentare la casa dei Laurens, dove aveva 
incontrato, tra gli altri, Pierre Louÿs. È infatti in questo milieu culturale particolarmente vivace che si è compiuta l'iniziazione di Gide alla letteratura e al mondo intellettuale dell'epoca.

4 Come testimonia la lettera di Gide datata 27 settembre 1934, gli ultimi messaggi sono certamente tra i più intensi e rappresentativi. La morte di Laurens, che sola porrà fine $\mathrm{a}$ questo legame, restituisce tutto il significato di questa amicizia. Rivolgendosi a Berthe, vedova dell'artista, lo scrittore afferma: «hier soir j'appris que tout était fini...» (p. 206). Prendendo coscienza della separazione dall'amico, Gide manifesta, per la prima volta, la consapevolezza di aver vissuto una condivisione profonda e per lui essenziale. La sua inconsolabile tristezza è affidata al figlio dell'amico: «Je ne me console pas, ne me consolerai pas de ce deuil. Le souvenir que je garde de lui n'a rien que de lumineux, que d'exquis et de tendre. Il est bien rare qu'une amitié puisse durer longtemps sans traverses; la nôtre n'en avait jamais connu» (p. 207). 